\title{
CONTRIBUIÇÕES DAS COMISSÕES DE INTEGRAÇÃO ENSINO-SERVIÇO NA EDUCAÇÃO PERMANENTE EM SAÚDE
}

\author{
CONTRIBUTIONS OF TEACHING-SERVICE INTEGRATION COMMISSIONS IN CONTINUING \\ EDUCATION IN HEALTH
}

\author{
CONTRIBUCIONES DE LAS COMISIONES DE INTEGRACIÓN ENSEÑANZA-SERVICIO \\ EN LA EDUCACIÓN PERMANENTE EN SALUD
}

Luiz Anildo Anacleto da Silva ${ }^{1}$

Marinês Tambara Leite ${ }^{2}$

Camila Pinno ${ }^{3}$

Resumo As comissões de integração ensino-serviço têm um importante papel para a efetivação da Política Nacional de Educação Permanente em Saúde. Neste estudo qualitativo, descritivo e exploratório, objetivou-se conhecer os fatores que potencializam ou fragilizam a construção e o desenvolvimento dos planos regionais de educação permanente na concepção dos membros participantes das comissões de integração ensino-serviço do estado do Rio Grande do Sul. A amostra de participantes ocorreu pelo método proposital, intencional ou deliberado. Os resultados evidenciam a importância de tais comissões no desenvolvimento dos planos regionais de educação permanente em saúde. São considerados fatores facilitadores: a participação e o envolvimento dos profissionais, a estruturação dos serviços. Os fatores limitadores são as dificuldades de articulação, participação e envolvimento pessoal e institucional; e a participação dos gestores. O envolvimento dos gestores no processo é dual: seu conhecimento e envolvimento são considerados fatores facilitadores, enquanto o desconhecimento e a não facilitação na inserção no processo educativo são entendidos como prejudiciais ao desenvolvimento do processo como um todo.

Palavras-chave comissão de integração ensino-serviço; educação permanente em saúde; processo de trabalho.
Abstract The teaching-service integration commissions play an important role in the realization of the National Policy for Continuing Education in Health. The purpose of this qualitative, descriptive study was to get to know the factors that enhance or weaken the construction and development of regional plans for continuing education in the view of the members participating in the teaching-service integration commissions in the state of Rio Grande do Sul (South Brazil). The participant sample was comprised based on the purposeful, intentional or deliberate method. The results show the importance of such commissions in the development of regional plans for continuing health education. The professionals' participation and involvement and the structuring of the services are considered facilitating factors. Limiting factors, meanwhile, are difficulties in coordination, participation, and personal and institutional involvement, in addition to the participation of the managers. The managers' involvement in the process is dual: their knowledge and involvement are considered facilitating factors, while ignorance and failure to facilitate insertion in the educational process are seen as harmful to the development of the process as a whole.

Keywords teaching-service integration commission; continuing health education; working process. 


\section{Introdução}

O desenvolvimento desta pesquisa teve como desígnio conhecer as numerosas acepções que envolvem a educação permanente em saúde (EPS) e embasam as propostas educativas; entender como ocorre a participação dos trabalhadores em saúde na elaboração dos planos regionais de EPS; e as potencialidades e fragilidades sentidas e evidenciadas encontradas na construção das propostas educativas. Em razão da extensão dos dados, neste texto abordaremos os fatores que interferem no desenvolvimento da EPS, com base no entendimento dos membros participantes das comissões permanentes de integração ensino-serviço (CIESs) do estado do Rio Grande do Sul.

A EPS constitui-se em uma das alternativas mais efetivas de superação de práticas alienantes e alienadas que estão desvinculadas das reais necessidades dos sujeitos, sejam esses trabalhadores, sejam usuários. Basicamente, partimos do princípio de que o processo educativo destina-se a fundamentar as atividades dos trabalhadores, permitindo a estes transcenderem no entender, conceber e fazer em saúde, de modo que possam contribuir para a geração de conhecimentos capazes de mediar propostas efetivas no processo de saúde e doença, bem como efetivamente articular ações curativas com atos de prevenção e promoção.

Concebemos a EPS como integrativa e vinculada internamente ao processo de trabalho, com a valorização dos saberes e práticas, em que não há sobreposição de educadores sobre educandos em razão de a educação, nessa concepção, ser mediada pelo diálogo entre os diferentes sujeitos, que incorporam conhecimentos como forma de empoderamento. Nessa perspectiva, visualiza-se a educação como a apropriação de saberes socialmente construídos que são continuamente produzidos e socializados (Silva e Backes, 2007).

Nesses termos, a educação se dá para, com e pelos sujeitos, e é em razão destes e da vinculação com o compromisso social que se projeta a educação no trabalho (Silva e Backes, 2007). O ponto de partida da educação para a compreensão da realidade é a contextualização da prática social, na qual educadores e educandos contribuem para o entrelaçamento de diferentes experiências e conhecimentos. O processo de trabalho em saúde vincula-se intrinsecamente ao processo em saúde, o qual se coaduna com um determinado modo de produção, que se concretiza em uma dada formação social articulada com as estruturas sociais e suas relações (Pereira, Soares e Campos, 2006).

A EPS está intrínseca e extrinsecamente atrelada ao processo laboral (atenção, gestão, educação), cujo objetivo é fomentar o trabalho multiprofissional e sua integralidade, articulado às necessidades de todos os segmentos envolvidos, gestores, trabalhadores e usuários.

A proposta de EPS, preconizada pelo Ministério da Saúde, estrategicamente prevê transformar e qualificar as ações e os serviços, os processos for- 
mativos e, ainda, as práticas pedagógicas e de saúde. Ela preconiza uma educação que tem como base a aprendizagem significativa (Brasil, 2005). Nesses termos, a educação permanente busca transformar as práticas profissionais existentes por meio de respostas construídas mediante a reflexão de trabalhadores, estudantes e demais atores sociais. Assim, essa proposta pode ser entendida como 'aprendizagem-trabalho', pois acontece com base no cotidiano das pessoas e das organizações (Brasil, 2005).

Na concepção de EPS proposta pelo Ministério da Saúde, procura-se integralizar o processo educativo, ao permitir a participação de vários segmentos sociais, em especial os prestadores dos serviços e os sujeitos-usuários, estabelecendo-se estes objetivos primordiais: a consolidação e o fortalecimento do Sistema Único de Saúde (SUS). Nessa proposta, parte-se dos princípios que orientam esse sistema, ou seja, a construção descentralizada; a universalidade; a integralidade; e a participação popular. A EPS busca possibilitar, concomitantemente, o desenvolvimento pessoal e institucional, assim como fortalecer as ações de formação com a gestão dos serviços e controle social (Brasil, 2005).

Nas questões concernentes à EPS, as CIESs têm um papel preponderante na condução da Política Nacional de Educação Permanente em Saúde (PNEPS), a qual se dá por meio dos colegiados de gestão regional (Cogeres). As CIESs são instâncias intersetoriais e interinstitucionais permanentes que participam da formulação, da condução e do desenvolvimento da Política de Educação Permanente em Saúde (Brasil, 2007).

As CIESs deverão ter em suas composições os gestores municipais, estaduais e do Distrito Federal. Dependendo das especificidades regionais, poder-se-á contar com os gestores estaduais e municipais de educação, os representantes dos trabalhadores do SUS e, ainda, as instituições de ensino com cursos na área da saúde e os movimentos sociais ligados à gestão das políticas públicas de saúde (Brasil, 2007).

No estado do Rio Grande do Sul, a condução da PNEPS cabe aos colegiados de gestão regional (Cogeres), com o apoio das CIESs regionais, que estão vinculadas às coordenadorias de regionais de saúde (CRSs) dos respectivos territórios. Portanto, as CIESs estão distribuídas de acordo com as macrorregiões concernentes às CRSs: Região Metropolitana ( $\left(1^{\mathrm{a}}, 2^{\mathrm{a}}, 18^{\mathrm{a}} \mathrm{CRS}\right)$, Centro-Oeste (4 $\left.4^{\mathrm{a}}, 10^{\mathrm{a}} \mathrm{CRS}\right)$, Missioneira $\left(9^{\mathrm{a}}, 12^{\mathrm{a}}, 14^{\mathrm{a}}, 17^{\mathrm{a}} \mathrm{CRS}\right)$, Norte $\left(6^{\mathrm{a}}, 11^{\mathrm{a}}\right.$, $\left.15^{\mathrm{a}}, 19^{\mathrm{a}} \mathrm{CRS}\right)$, Serrana ( $\left.5^{\mathrm{a}} \mathrm{CRS}\right)$, dos Vales $\left(8^{\mathrm{a}}, 13^{\mathrm{a}}, 16^{\mathrm{a}} \mathrm{CRS}\right)$ e Sul $\left(3^{\mathrm{a}}, 7^{\mathrm{a}} \mathrm{CRS}\right)$ (Rio Grande do Sul, 2007).

A CIES-RS é composta por um representante de cada CIES regional, totalizando 19 pessoas como membros natos; dois representantes do gestor estadual da saúde; dois dos secretários e dirigentes municipais de saúde; um do gestor estadual da educação; um dos gestores municipais de educação; oito dos trabalhadores de saúde; seis das instituições de ensino com cursos 
na área da saúde (três de nível técnico e três de nível superior, com representação de docentes, discentes e técnicos administrativos); cinco dos movimentos sociais; dois dos conselheiros municipais de saúde, com pelo menos um do segmento usuário; dois dos conselheiros estaduais de saúde, com pelo menos um do segmento usuário. O número total de membros previsto na lei é de 48 conselheiros (Rio Grande do Sul, 2011).

As atribuições da CIES estadual estão em prestar assessoria em assuntos que tratem da EPS; monitoramento e avaliação da implementação da política de formação e desenvolvimento no âmbito do SUS e das ações e estratégias relativas à educação em saúde, constantes no Plano Estadual de Saúde, nos planos regionais de educação permanente em saúde; estimular a participação dos gestores, trabalhadores em saúde, instituições de ensino e instâncias de participação social; articular, juntamente com o poder público e as instituições formadoras, estabelecimentos de saúde, instâncias do controle social e movimentos sociais, estratégias de intervenção no campo da formação e no desenvolvimento dos trabalhadores, tendo por princípio os conceitos e diretrizes da EPS em consonância com o SUS (Rio Grande do Sul, 2011).

Neste estudo, pressupomos que o desenvolvimento sistematizado de educação no trabalho permitirá aos trabalhadores continuamente desenvolver conhecimentos vinculados às suas necessidades/realidades. A questão de pesquisa busca elucidar quais as potencialidades e fragilidades evidenciadas por membros participantes da CIES estadual no que se refere à construção dos planos regionais de EPS. Nesta pesquisa, objetivou-se 'conhecer os fatores que potencializam ou fragilizam a construção e o desenvolvimento dos planos regionais de educação permanente na concepção dos membros participantes das CIESs regionais do estado do Rio Grande do Sul'.

\section{Referencial metodológico}

Metodologicamente, esta pesquisa classifica-se como qualitativa, descritiva e exploratória (Minayo, 2007; Gil, 1996). Os sujeitos da pesquisa foram os integrantes da CIES estadual (gestores; docentes e discentes; trabalhadores; membros do controle social), que, espontaneamente, concordaram em assinar o termo de consentimento livre e esclarecido (TCLE) e participar do estudo.

A amostra dos sujeitos da pesquisa ocorreu pelo método proposital, intencional ou deliberado (Turato, 2003), ou seja, foram convidados a participar representantes dos gestores, trabalhadores, docentes e discentes das instituições de ensino e do controle social. A amostra final constitui-se de vinte sujeitos. Na apreciação dos dados, utilizou-se a técnica de análise de conteúdo (Bardin, 2011). 
A pesquisa seguiu os preceitos éticos que envolvem seres humanos, em conformidade com o que prevê a resolução do Conselho Nacional de Saúde, portaria n. 196/96 (Brasil, 1996), obtendo a aprovação do Comitê de Ética em Pesquisa da Universidade Federal de Santa Maria (parecer consubstanciado n. 23081.001363/2009-51).

A opção pelo modelo de amostra deu-se em razão de que tínhamos a intenção de entrevistar, em ordem sequencial, membros das CIESs de acordo com a sua representatividade, ou seja, trabalhadores, gestores, docentes, discentes e controle social. A representação dos sujeitos da pesquisa foi composta de dois administradores, um odontólogo, um farmacêutico, um assistente social, representando os gestores; um enfermeiro, uma nutricionista, um auxiliar de enfermagem e dois técnicos de enfermagem, pelo segmento trabalhador; um arquiteto, um auxiliar de planejamento, um de serviços gerais, um administrador e um educador popular na representação dos usuários - estando as instituições de nível superior representadas por dois docentes e dois discentes de enfermagem e um de psicologia.

Após todos os trâmites legais na consecução da coleta de dados, solicitou-se à coordenação estadual da CIES autorização para participar das reuniões mensais, em que estivessem presentes os conselheiros advindos de diferentes regiões do estado, e também das distintas representações, conforme proposto na amostra. No primeiro encontro, foi feita a apresentação dos objetivos da pesquisa aos conselheiros, com o esclarecimento de dúvidas sobre o estudo. Posteriormente, fizeram-se a abordagem individual e a solicitação da assinatura do TCLE para participar da pesquisa. Durante a coleta de dados, um dos pesquisadores participou de seis reuniões da CIES estadual, o qual também já havia participado das reuniões de uma das CIESs regionais.

Incluíram-se como sujeitos da pesquisa aqueles que se dispuseram a assinar o TCLE e participar do estudo, e excluíram-se os sujeitos que não quiseram assinar o termo ou participar do estudo, bem como quando havia repetição da amostra. Os sujeitos, neste texto, são identificados pela letra 'E' (Entrevistado), seguindo-se um número sequencial de identificação.

\section{Resultados}

As informações advindas dos dados da pesquisa permitiram a construção de quatro categorias. A primeira refere-se à importância das 'comissões de integração ensino-serviço: participação e envolvimento nos programas'. A segunda focaliza a 'estruturação dos serviços'. A terceira e a quarta categorias referem-se à 'articulação, a participação e o envolvimento pessoal e institucional' e à 'participação dos gestores', respectivamente. 


\section{Comissões de integração ensino-serviço: participação e envolvimento nos programas}

Dos vinte entrevistados, 13 salientaram a importância das CIESs como fórum de discussões, assim como o envolvimento institucional e pessoal dos sujeitos nas decisões e definições das propostas que constituíram os planos regionais de EPS. A importância da CIES no desenvolvimento das ações edu-cativas é realçada, em especial, na participação e na implantação dos planos de EPS. Os planos regionais de educação são socialmente construídos e servem de parâmetros ao desenvolvimento das propostas educativas e à aplicabilidade das ações educativas. A participação e o envolvimento dos diferentes segmentos estão assim enunciados:

Todos os atores envolvidos no CIES nas tomadas de decisões (E1).

Novos processos implementados na Comissão Integrada de Ensino e Serviço (E2).

Os fatores que facilitam as propostas de educação permanente estão na composição mista das CIESs, bem como a equipe técnica responsável pelas ações junto à Coordenadoria de Saúde (E17).

Entendo que a participação envolve os municípios e as respectivas necessidades, bem como na participação do Cofen [Conselho Federal de Enfermagem] e das CIESs (E18).

A cooperação das instituições, a participação dos membros da CIES, o interesse dos(as) secretários(as) de saúde dos municípios para que ocorram estas capacitações e o interesse dos trabalhadores de saúde em participar e se qualificar (E19).

O entendimento dos entrevistados reflete a importância das CIESs na condução dos planos regionais de EPS, conforme estabelecido na portaria n. 1.996/2007 (Brasil, 2007). Nesta forma de ver, evidencia-se o papel da CIES na implementação da EPS, principalmente no que tange às articulações interinstitucionais, nas formas de apoiar e intervir com propostas de materializar conhecimentos e práticas já existentes, além de desenvolver novas tecnologias no campo da assistência, da gestão e da educação.

$\mathrm{Na}$ organização das CIESs, com relação a uma regional especificamente ou estadual, preconiza-se que nela estejam inseridas a representação de diversos segmentos. E é essa multiplicidade que efetivamente permite a congregação de diferentes olhares, interesses e necessidades, os quais darão sustentação às propostas educativas, nos respectivos planos regionais ou estadual de educação permanente. 
A ativa participação dos sujeitos na elaboração e na apreciação é preponderante para que as propostas educativas inseridas nos planos regionais estejam de acordo com as necessidades dos sujeitos (trabalhadores ou usuários), grupos ou populações. A constituição das CIESs, conforme estabelecido em lei (Brasil, 2007; Rio Grande do Sul, 2011), preconiza que haja representação e cooperação de órgãos de classe, associações e outras entidades representativas, pelas contribuições no delineamento das propostas educativas. As comissões de integração ensino-serviço regionais são o primeiro fórum de discussões e de construções coletivas em conformidade com as necessidades e as demandas de educação permanente em saúde. É nas CIESs regionais que se esboçam as propostas educativas que vão constituir os planos regionais de educação permanente.

Mehry, Feuerwerker e Ceccim (2006) explicitam que a proposta de EPS está articulada com estes objetivos: produzir novos pactos e acordos coletivos para o SUS; ter como foco o processo de trabalho: atenção, gestão, educação e formação; atuar de forma integrativa com enfoque multiprofissional e interdisciplinar; trabalhar na geração de coletivos organizados para a produção e a gestão de recursos humanos; e possibilitar a construção de estratégias de maior potencialidade.

Preconiza-se que as coordenadorias regionais sejam detentoras de conhecimentos sobre as questões atinentes à saúde, a recursos materiais, equipamentos e recursos humanos nos seus respectivos territórios. As inserções das CIESs nas coordenadorias regionais de saúde podem representar avanços no que tange à construção de pactos nos quais seja possível construir ações que redimensionem e rearticulem propostas educativas congruentes com o processo de trabalho em saúde.

Na definição das propostas de EPS, Mehry, Feuerwerker e Ceccim (2006) afirmam que a definição dos conteúdos é ascendente, a partir dos coletivos e dos processos de trabalho que identificam a natureza das necessidades educativas. Dessa forma, permite-se a construção efetiva de propostas de EPS. Porém, a construção de propostas educativas, desenvolvidas de acordo com os preceitos da EPS e que, consequentemente, tenham 'significado' para os sujeitos, precisam estar articuladas com as 'necessidades', assim como estar vinculadas e desenvolvidas em diferentes momentos e cenários, de forma especial nos espaços de trabalho. A participação e o envolvimento dos diversos atores dão sustentação às propostas educativas e as sedimentam, situando-se as CIESs como um dos principais fóruns de discussões.

Destacam Ricaldoni e Sena (2006) que o desafio da educação permanente está em estimular o desenvolvimento da consciência dos sujeitos em relação ao seu contexto, bem como seu envolvimento, participação e responsabilidade em seu processo educativo. Para que isso se torne efetivo, 
porém, é necessário rever os métodos de EPS utilizados, com processos sistematizados e participativos, tendo como cenário o próprio espaço de trabalho, no qual pensar e fazer são fundamentais no processo de aprender, ensinar e trabalhar.

A participação da academia nas CIESs representa a necessária interlocução do que se preconiza nas teorias e do que se evidencia no campo das práticas - ou seja, a teoria se experimenta na prática, e é na prática que se absorve ou se refuta a teoria. Aos docentes e discentes, essa experiência não representa uma simples 'experimentação', mas sim a imersão em um espaço diferenciado, na qual o 'saber' e o 'fazer' se aproximam e, reciprocamente, se potencializam. Nesta concepção, as ações transcendem das práticas isoladas para ações coletivas, havendo efetivamente a integração docente-assistencial.

Por sua vez, os sujeitos da pesquisa destacam a diversidade de situações conforme suas necessidades ou expectativas, evidenciando a importância que representa o engajamento de outros atores, situações e instituições. Sobre esse aspecto, salientam:

Eu vejo a importância da história da região de desenvolvimento de atividades interinstitucionais (instituições de ensino superior, coordenadoria e secretarias municipais de saúde) desde antes da política da EPS (E6).

É importante a integração com as instituições formadoras na formulação e na implementação de projetos político-pedagógicos que superem a visão tradicional, vendo o SUS como local e a universidade/escolas técnicas como campo de conhecimento (E7).

Para isso, tem que ter a mobilização dos atores, o desejo de mudança no processo de trabalho/práticas de gestão (E8).

Aqui nessa região ter um fórum regional permanente de saúde mental, um Conselho Gestão no Centro Regional de Referência em Saúde do Trabalhador, ambos em participação de trabalhadores, assim como estes estão se organizando para participar mais dos conselhos de saúde (E9).

As facilidades, no meu entendimento de hoje, são em relação à educação permanente. A comunicação é um fator fundamental para divulgações destas propostas (E12).

Instituições e ONGs são fundamentais para esta caminhada (E13).

Tem que garantir a liberação da carga horária de pessoas da gestão para acompanharem e até sustentarem o espaço da CIES (E10). 
Embora haja uma diversidade de respostas, o intento é comum: o desejo de mudanças. Mesmo que de maneira diferenciada, os entrevistados sinalizam para um mesmo propósito: que se considere a historicidade regional, que haja a integração dos diversos segmentos, que a construção seja coletiva e que se desenvolvam ações que efetivamente estejam de acordo com as necessidades de aperfeiçoamento profissional dos trabalhadores e, consequentemente, possam aprimorar a gestão e, sobretudo, a atenção em saúde.

A participação de diversos atores, a partir do que propicia a CIES, evidencia-se no momento em que os sujeitos enfatizam a necessidade do diálogo e da construção coletiva.

Ainda que se mantivesse sempre aberta a novos interessados, estabelecer datas para reuniões e fortalecer seu funcionamento e a construção de um espaço de discussão e compartilhamento (E14).

O diálogo entre a coordenadoria e secretarias, o Gogere, a disponibilidade de horários dentro da carga horária semanal para a realização dos aperfeiçoamentos, a corresponsabilidade para a execução das propostas, a informatização, os materiais didáticos e os profissionais capacitados (E15).

Poder contar com pessoas do quadro de funcionários, tanto na esfera estadual como municipal, que fazem parte do grupo que se encontra para definir ações de educação continuada, além das universidades (E16).

As CIESs regionais disponibilizam uma agenda de encontros que facilitam a inserção e a participação dos sujeitos, constituindo-se essas reuniões em um importante ambiente de discussões, trocas de experiências. Os problemas do cotidiano e dos respectivos espaços de trabalho embasam as construções coletivas que sedimentam as propostas contidas nos planos regionais de educação permanente em saúde.

A integração docente-assistencial constitui-se em um dos alicerces sobre os quais se fundamentam os processos de transformação na educação dos profissionais e dos sistemas de saúde, o que se expressa especialmente pelas articulações universidade-serviço, universidade-comunidade e serviço-comunidade, as quais têm em seus princípios o processo de construção permanente (Albuquerque et al., 2008).

Para Santos Filho e Figueiredo (2009), a concepção de cogestão pressupõe a ampliação dos espaços públicos e coletivos, viabilizando o exercício do diálogo e da pactuação de diferenças. A concepção de cogerir embasa a possibilidade de construção compartilhada de conhecimentos e intervenções, considerando as subjetividades e singularidades dos sujeitos e coletivos. 
Para Barrios (2009), os Cogeres constituem-se em importantes espaços para construção de significados, possibilitando a criação de fluxos de ideias, de debates, negociação e compromissos que venham colaborar com a instituição e também para o desenvolvimento das pessoas como sujeitos e como grupo. Para tanto, o Colegiado de Gestão Regional constitui-se em um espaço de articulação de permanente repactuação e cogestão solidária entre os diferentes sujeitos, tendo como principal característica ser um espaço de pactuação, planejamento e gestão solidária, de arranjos institucionais compostos por gestores de diferentes esferas de governo. Portanto, as ações das CIESs com os respectivos Cogeres regionais configuram-se em importantes espaços de discussão para avaliação, redefinição, reconfiguração dos planos regionais e a consequente implementação dos programas de educação permanente em saúde.

\section{Estruturação dos serviços}

A segunda categoria refere-se à definição das condições e da consequente estruturação dos serviços e também à viabilização dos programas de EPS. Nessa ótica, compreende-se que a PNEPS tem um papel de avalizar a construção dos planos regionais de educação permanente.

Um dos grandes avanços da área foi a garantia de financiamento, através de legislação federal específica (E7).

O apoio financeiro possibilita a organização de cursos, palestras e demais ações (E17).

O financiamento da EPS está previsto na portaria n. 1.996/2007, o que assegura o suporte econômico e financeiro para a efetivação da PNEPS (Brasil, 2007). As CIESs regionais têm à sua disposição orçamento próprio para ao financiamento das propostas educativas, contidas nos planos regionais de educação permanente em saúde.

\section{A articulação, a participação e o envolvimento pessoal e institucional}

A articulação, a participação e o envolvimento pessoal e institucional, quando presentes, são destacados como fatores facilitadores, uma vez que a não evidência deles é sentida como um dos principais entraves na implantação de propostas educativas, constituindo-se dessa forma em fatores limitadores da implantação da EPS.

A articulação e a integração entre instituições do setor da saúde e aos da educação são dificultadas pelas diferentes estruturas destes dois setores (CIES e Cogere) (E6). 
São as ações fragmentadas das políticas e programas de saúde, muito presentes em nosso cotidiano, que atrapalham qualquer projeto de mudança (E7).

Os docentes e discentes têm pouca participação (E8).

Há uma insuficiente participação dos servidores (E11).

A falta de engajamento e colaboração por parte de alguns membros e equipe, bem como a falta de pessoal nas coordenadorias (E13).

O controle social e os movimentos sociais ainda possuem uma participação incipiente. Por isso, compreendo que um dos grandes desafios para a educação permanente é a educação permanente de conselheiros, para a defesa das políticas sociais (E20).

Falta de sensibilização em torno da proposta para entender que a educação e a pesquisa são processos permanentes na vida de todos os profissionais e um constante aprendizado (E12).

Entre os desafios a serem transpostos nas CIESs está o aprimoramento da integração institucional, tanto com a academia quanto com outras organizações, em especial com o Cogere. Mas, sobretudo, mediante a ação de propor e ampliar discussões a respeito do processo de trabalho em saúde. A redefinição do processo de trabalho inclui superar a compartimentação e desenvolver a atenção, a gestão e a educação de forma conjugada, e articular ações de forma que os programas educativos estejam conectados com as políticas de saúde.

Embora se observe que há uma boa articulação entre ensino e serviço, há de se ressaltar que essa articulação precisa ser aprimorada, assim como é preciso criar mecanismos que promovam ativamente a participação dos docentes e discentes nas CIESs, sobretudo em discussões que permitam a aproximação entre docentes, discentes e trabalhadores na construção de programas educativos congruentes com a atenção e a gestão.

Silva e Backes (2007) destacam que o desafio na ampliação das ações educativas no trabalho está em transcender da compartimentação para fazer surgirem propostas de educação que permitam maior participação dos sujeitos no processo e que sejam institucional e socialmente construídas. A ação educativa no trabalho pode ocorrer mediante a construção de espaços coletivos para avaliar as formas de projetar e intervir educativamente e refletir sobre elas.

A EPS, desse modo, destina-se à qualificação dos trabalhadores no sentido de desenvolver potencialidades pessoais, sociais e profissionais, ou 
seja, o desenvolvimento integral dos sujeitos. Contudo, precisa-se dizer que a educação preconizada pela EPS transcende o aperfeiçoamento técnico. Nesta, incluem-se o direito à cidadania, garantias de saúde, condições dignas de trabalho e possibilidades de ascensão profissional.

No entanto, a compartimentação não ocorre somente no processo de trabalho em saúde; tal cisão também ocorre na educação. Almeida e Rocha (1986) destacam que o saber técnico e científico, parcelado e dividido tecnicamente, subordina-se às imposições e aliena os trabalhadores no processo de trabalho. Retomando a questão inerente ao processo de trabalho, Pires (2008) afirma que os profissionais de saúde, independentemente de suas especificidades de conhecimentos e de práticas, são parte de um conjunto: a atenção. Transparece no estudo que institucionalmente, de forma geral, não se trabalha com planejamento e não se costuma inserir os trabalhadores no 'pensar e organizar o trabalho'. Assim, perde-se a riqueza de uma visão ampliada pela percepção dos diferentes segmentos profissionais, não havendo integração interdisciplinar, a qual poderia significar avanços em termos de qualificação do trabalho.

Em se tratando de atenção à saúde, a interação e a integração das ações educativas estão relacionadas à construção de saberes ampliados e que possam se constituir mediante o conhecimento e as experiências dos trabalhadores, numa situação tal que considere o local de trabalho como espaço educativo no qual os trabalhadores são parte de um contexto histórico-social, bem como detentores de um conhecimento que deve ser valorizado. Esse conhecimento, que tem como base o saber próprio dos trabalhadores e é oriundo de uma prática do seu fazer cotidiano de trabalho, não se restringe somente à técnica, mas atinge os laços profissionais e interpessoais que compõem as relações de trabalho (Azambuja, 1999).

\section{Participação dos gestores}

A quarta categoria está vinculada à participação dos gestores como fator limitador. Tal qual a questão da estruturação dos serviços, a participação destes é dual. Quando há investimento/facilitação nas ações educativas por parte dos gestores, ocorrem ganhos para todos os segmentos envolvidos, e quando há restrição, acontecem dificuldades na implantação e no desenvolvimento das ações educativas.

Não há comprometimento dos gestores, pois não participam dos movimentos sociais (E2).

Não há interesse dos gestores, em geral, em proporcionar condições de capacitar e melhorar as ações dentro das políticas nacionais de saúde (E4). 
Os problemas de gestão se traduzem na sobrecarga dos profissionais, política partidária e não de saúde, em que os trabalhadores não se sentem sujeitos e sim funcionários do prefeito, do secretário (E8).

Muitos gestores correlacionam a questões partidárias as políticas da CIES, nas quais as pessoas acabam entrando neste mesmo rol (E18).

Um dos fatores se relaciona à demora dos projetos serem aprovados. Precisam de várias etapas como reuniões, Cogere, CIES regional, estadual, até a provação final. Isso leva um tempo, de forma que a data escolhida, às vezes, tem que ser mudada, dificultando a realização do projeto e até a de outros (E19).

Em relação aos CIES e à educação permanente, Barrios (2009) considera que entre as atribuições dos conselhos regionais de gestão está servir de espaço para a produção de pactos, em razão de serem locais onde os integrantes são informados dos projetos, embora possam não ter participado efetivamente de sua construção. Para o autor, os gestores nem sempre têm a real compreensão do papel da comissão e, consequentemente, não constroem parcerias para discutir a EPS, em razão de muitos gestores desconhecerem as especificidades da educação permanente.

A EPS pode, no entanto, ser uma importante estratégia de mudanças, de gestão participativa e construção coletiva com os diferentes atores que integram os espaços regionais. Contudo, ainda predominam, na pauta de discussão, os cursos pontuais de capacitações, ofertados principalmente em decorrência das demandas que têm emergido dos gestores municipais, coordenadorias e cursos formadores organizados por instituições de ensino, distanciando-se dos preceitos que dão significado à educação permanente (Barrios, 2009). A EPS, para ter sentido e produzir mudanças no processo de trabalho, precisa estar em sintonia com as demandas advindas dos gestores municipais ou regionais; carece ter congruência com as necessidades dos trabalhadores e usuários.

Essa forma de organização coloca a CIES em uma posição de subordinação em relação aos Cogeres, o que dificulta o engajamento dos trabalhadores na elaboração de propostas de ações educativas capazes de reorientar os trabalhadores para refletirem sobre seu fazer e, consequentemente, repensarem a organização dos seus espaços de trabalho e os serviços de saúde (Barrios, 2009).

Quando se fala em gestão, o que primeiro ocorre é a noção de alguém ou um grupo que concebe e determina uma ação e outro a executa. Afinal, a participação dos trabalhadores nos processos de gestão é algo ainda incipiente, não perceptível e palpável no cotidiano das organizações, em especial na saúde, razão pela qual o processo de trabalho em saúde ainda permanece fragmentado e parcelado. 
No contexto em que se desenvolveu este estudo, os trabalhadores em saúde têm pouca participação nas decisões sobre seus espaços de trabalho, por estarem vinculados à excessiva burocracia, a formas equivocadas de organização, a uma gestão centralizadora e pouco engajada no sistema de saúde. A gestão participativa pode, então, ser considerada um valioso instrumento de mudanças, contribuindo para a qualificação dos serviços. A cogestão é assim uma forma de superar o instituído, ao ofertar condicionantes que permitam incluir na gestão o pensar e o fazer coletivos (Brasil, 2007).

Um novo desenho de gestão precisa ser congruente com uma nova forma de concebê-la. Para tanto, urge desenvolver ações integrativas de atenção, gestão e educação, com o partilhamento dos processos de decisão, engajamento, desfragmentação das organizações e dos processos de trabalho e responsabilidades, horizontalização organizacional - ações essas dispostas, principalmente, a romper com o paradigma segundo o qual aos gestores cabe a 'concepção' e aos trabalhadores a mera 'execução' (Brasil, 2009).

A posição adotada pelos gestores em relação às CIESs tem uma posição dual: quando eles reconhecem na PNEPS a importância da educação como elemento de desenvolvimento pessoal, institucional e social, entre outros fatores, que são atribuições da CIES, seu comportamento é pelo incentivo, facilitação e participação nos programas educativos. Contudo, quando os gestores desconhecem as propostas de EPS e fazem uso não adequado da política, como a partidarização das ações e opções imediatistas com ênfase nas ações curativas e na medicalização, por vezes não se verificam incentivos e facilitação, até mesmo havendo restrições à participação nas CIESs ou nas ações de educação permanente.

\section{Discussão}

As respostas dos sujeitos pesquisados, associadas e à convivência entre os membros da CIES, subsidiam o delineamento, planejamento, configuração e implantação dos planos regionais de EPS. As composições das CIESs regionais e estadual, com a representação dos diversos segmentos profissionais e sociais, permitem melhorar as condições de interação e aproximação entre os diferentes segmentos, sejam esses trabalhadores, sejam usuários ou a comunidade. Em se tratando da academia, a participação desta, nas CIESs regional ou estadual, consente verdadeiramente a integração entre docentes, discentes e os serviços.

Não obstante, evidenciam-se problemas cruciais, como o desconhecimento dos sujeitos sobre a função das CIESs e a importância que representa a EPS nas transformações do processo de trabalho. Um fato manifesto refere-se aos gestores. Quando estes estão investidos de conhecimentos sobre as atribui- 
ções da CIES, normalmente incentivam as discussões e participam ativamente delas, procurando contribuir para a construção de programas educativos diferenciados que podem ser geradores de importantes mudanças.

Entre os quatro segmentos de conselheiros pesquisados (trabalhadores, gestores, ensino e controle social), embora se tenham diferentes olhares sobre educação e saúde, eles têm entendimento de que as dificuldades sentidas e evidenciadas não estão nas CIESs propriamente ditas, mas primordialmente no contexto dos serviços de saúde. Nesse fator limitador incluem questões de organização, na qual a base se assenta na tríade consultas/exames/medicações; e de educação, em que a prevenção e a promoção em saúde estão em um plano secundário.

A educação tanto aos profissionais como aos usuários se dá de forma de distanciada do diálogo e da construção coletiva. Desse modo, aos profissionais o enfoque é dado para a solução de questões técnicas e pontuais. Já aos usuários ela acontece, normalmente, em grupos de hipertensos/diabéticos e são 'diretivas e prescritivas', sob a forma de 'orientações' e, muitas vezes, condicionando a participação desses nos grupos com a liberação de fármacos de uso contínuo.

Retomando a questão da importância da CIES na construção de propostas educativas que constituem os planos regionais de EPS, há de se destacar que socialização entre as equipes significa maior aproximação 'entre o que se necessita e o que se é ofertado'. A construção de propostas calcadas nas necessidades dos sujeitos, sejam esses trabalhadores, sejam usuários, interiormente significa repensar o processo de trabalho.

A concepção de EPS e o estabelecimento das CIESs como foco de discussão dos preceitos e das práticas educativas representam um marco nas transformações da educação em saúde e, de maneira especial, no processo de trabalho. A remodelagem das propostas educativas está em romper com a alienação dos sujeitos, assim como em permitir mudanças que realmente impactem as formas de fazer a atenção em saúde. A educação é um dos caminhos para transformar um modelo 'centrado na doença' em um padrão 'centrado na saúde'.

Histórica e socialmente está demonstrado que investimentos em educação contribuíram para se obter importantes transformações em diferentes campos (econômico, financeiro ou tecnológico). Na saúde, verdadeiramente, a educação tem o compromisso com a promoção dos sujeitos, em especial no que se refere à cidadania e à responsabilidade social. Para tanto, precisa se prover um modelo educativo de forma que tenha impacto no processo de trabalho, levando os sujeitos a desenvolverem uma práxis criadora, inovadora e transformadora em substituição à práxis reiterativa e imitativa (Vázquez, 1997; Freire, 1998). A EPS está comprometida com a transformação, com o rompimento de paradigmas, por meio da construção coletiva 
de propostas educativas, e com a superação dos preceitos de conteúdos estanques, por considerar que a interação entre educadores e educandos constrói-se com ações dialógicas, em que se ensina aprendendo e se aprende ensinando (Silva et al., 2010).

Retomando a questão dos serviços de saúde, infere-se que a forma tradicional de gestão exclui a participação dos trabalhadores no planejamento e nas tomadas de decisão. Contudo, as formas diferenciadas de conduzir o processo de trabalho em saúde incluem novas estratégias, como gestão participativa, cogestão, clínica ampliada, humanização, ambiência, equipe de referência, apoio matricial, projeto transdisciplinar e terapêutico, acolhimento com avaliação de risco, entre outras propostas estruturantes (Brasil, 2004a, 2004b, 2004c, 2009).

Destaca-se que o desenvolvimento dessas propostas, fundamentalmente, encontra guarida na EPS, porque é por meio da educação que se podem gerar mudanças, capazes de inserir de maneira igualitária os sujeitos no processo de saúde. Ratificando: os preceitos teóricos que dão base à EPS podem significar a transcendência dos modelos educativos e também do processo de trabalho, no sentido de modificar a concepção de 'pensadores' e 'executores' para uma composição de educadores e educandos, que estão em patamares semelhantes. Essa situação poderá ser alcançada quando as propostas educativas, efetivamente, venham a ser socialmente construídas e, desta forma, se congregar em uma relação de educação que tenha 'significado coletivo'.

A concepção de gestão participativa e cogestão inclui os sujeitos nos processos de gestão, principalmente no que se refere à análise de contexto e problemas, bem como na tomada de decisões. Essa projeção de gestão inclui os trabalhadores também como gestores do seu processo de trabalho. Em virtude dos fatos elencados, isso implica a inserção dos sujeitos e grupos na definição dos rumos das organizações e nos espaços de criação, o que provoca o advento de novos ambientes de trabalho, um novo processo de trabalho e de ações educativas inovadoras de produção e de socialização de conhecimentos (Brasil, 2009).

A inclusão dos trabalhadores no processo de decisão significa (re)pensar as formas de organização da gestão, com a criação de condições políticas e institucionais efetivas e mais: com o desenvolvimento de arranjos e dispositivos que criem as condições essenciais para que isso de fato se concretize. A participação dos sujeitos nesse processo significa o compartilhamento de responsabilidades, novas relações de equipe, produção de subjetividades e reestruturação das organizações (Brasil, 2009).

A noção de trabalho na perspectiva da clínica ampliada significa redimensionar o processo de trabalho, ao se assumirem novas responsabilidades em relação aos usuários, em que a exequibilidade do trabalho assume a dimensão ética, o reconhecimento de limites e novas possibilidades de in- 
tervenção no processo de saúde e doença - como também abre novas possibilidades de intervenção e instauração de vínculos e afetos (Brasil, 2004a).

A instituição de novos padrões de atenção e gestão inclui a inserção das ações pertinentes e recorrentes características de um trabalho transdisciplinar e das ações terapêuticas, que, consequentemente, dependem também da instituição de novos padrões de relacionamento entre os profissionais de saúde e os usuários. Isso significa pensar novos padrões de atenção, gestão e educação, pois o processo decisório é deslocado também para os trabalhadores, situação tal que os coloca em outro patamar institucional. Nessa situação, eles passam de simples executores a coautores, o que normalmente implica maior compromisso e engajamento.

O envolvimento dos trabalhadores tende a gerar maiores compromissos e a incorporação de responsabilidades com a equipe e com os usuários quer dizer, de todos os sujeitos envolvidos no processo. Em virtude dessa mudança de paradigma, necessita-se incluir alterações na estrutura de gestão e de atenção, com a criação de novas formas de organização assistencial e gerencial, capazes de ver os sujeitos conforme suas necessidades e particularidades (Brasil, 2004b).

Portanto, a implantação das equipes de referência e apoio matricial significa conceber organizações que tenham como preceito a transversalidade, numa concepção dos serviços de forma que os sujeitos sejam vistos na sua integralidade. $\mathrm{O}$ apoio matricial é um arranjo organizacional de complementaridade das equipes de referência, ou seja, uma forma de organizar e ampliar as ações de saúde. Conceber, estruturar os serviços mediante os preceitos de equipes de referência e apoio matricial, portanto, são ações imprescindíveis para a humanização da gestão em saúde (Brasil, 2004b).

São propostas dessa natureza que podem permitir transcender as atuais formas de gestão, atenção e educação, pois elas ocorrem concomitantemente, não necessariamente nesta ordem de importância - ou seja, as ações são integrativas e se desenvolvem de forma sistematizada. Também é preciso dizer que com essa nova dinâmica, os sujeitos concebem e executam as ações, rompendo com a dicotomia existente nas formas tradicionais de gestão (Brasil, 2004a, 2004b, 2004c).

As transformações no campo de trabalho em saúde com a introdução da gestão participativa, cogestão, clínica ampliada, humanização, ambiência, equipe de referência, apoio matricial, projeto transdisciplinar e terapêutico, acolhimento com avaliação de risco, entre outras, significa rever e redimensionar todo o processo de trabalho. Essas mudanças são de importância fundamental na operacionalidade, nas atividades-fim de qualificação da atenção em saúde.

As CIESs representam um importante espaço de discussões e construções coletivas de projetos educativos, de intermediação e viabilização 
burocrática dos planos regionais ou estadual de EPS. É nas comissões de integração ensino-serviço que as transformações começam a tomar forma, sendo na educação permanente em saúde que elas efetivamente se concretizam.

\section{Conclusão}

Evidencia a pesquisa a importância que têm as CIESs regionais e estadual na articulação das políticas educativas, no fomento das propostas e no assessoramento para a construção dos planos regionais de educação permanente. A comissão de integração ensino-serviço congrega sujeitos que representam diversos segmentos profissionais e sociais e, de forma especial, insere a academia nas discussões, permitindo aos docentes e discentes participarem diretamente das discussões, o que provoca uma retroalimentação dos preceitos de educação permanente e educação em saúde que, abordados em sala de aula, aproximam os constructos teóricos das práticas efetivas, embora se ratifique que as demandas educativas ainda são pontuais, compartimentadas. Portanto, para que se obtenham as transformações nos espaços e, nos respectivos processos de trabalho, precisa-se de mudanças nas práticas profissionais e na sua organização, ao transacionar de maneira integrativa ações educativas, de atenção e gestão.

Outro fator facilitador refere-se à definição das condições e da estruturação dos serviços como forma de viabilização da EPS. Dentre as condições, pode-se considerar a política de EPS propriamente dita, assim como a dotação orçamentária financeira. A estruturação se refere à elaboração e à implementação dos planos de educação permanente via CIES, que incluem a articulação de ensino técnico, graduação e pós-graduação, assim como a definição de novas formas de monitoramento e avaliação.

São, por sua vez, considerados fatores limitadores a falta de articulação e envolvimento pessoal e institucional, as ações pontuais e fragmentadas, a pouca participação dos docentes e discentes, assim como a falta de engajamento das propostas e da coordenação e pouco envolvimento do controle social.

Outro fator limitante está relacionado à participação dos gestores, principalmente no que concerne ao não comprometimento, ao desconhecimento da EPS e da importância das ações educativas como forma de aperfeiçoar o processo de trabalho e, consequentemente, os resultados efetivos na saúde das populações e comunidades. Nesse caso, evidencia-se claramente a importância da participação do gestor.

A participação dos trabalhadores nos processos de gestão nos moldes tradicionais é ainda incipiente, por isso a (re)definição de gestão, com o estabelecimento de colegiados gestores com a inclusão dos trabalhadores e usuários, representa um espaço democrático de discussões e tomada de 
decisões, situação na qual tende-se a romper com a dicotomia de concepção e execução, muito característica de processos de trabalho de moldes capitalistas.

Embora os sujeitos da pesquisa tenham diferentes formações e representem distintos segmentos, 'os olhares' sobre as questões são assemelhados. Estes identificam que há problemas de gestão e, sobretudo, de processo de trabalho. Atinentes a isso, entendem a CIES como um importante espaço de discussão, construção e geração de mudanças.

A pesquisa ainda ressalta a importância que a CIES tem na constituição dos planos regionais de EPS. Contudo, há que se dizer que mesmo havendo fatores limitadores, estes não se referem às comissões de integração ensino-serviço especificamente, mas sim a questões contextuais, que histórica e culturalmente estão arraigadas nos sistemas de saúde no segmento pesquisado. Entre esses fatores, estão a falta de envolvimento e comprometimento das equipes, carência de profissionais, infraestrutura deficiente nas unidades básicas de saúde, problemas de acolhimento e acessibilidade aos serviços, organização e sistematização da atenção em saúde. Estes não são problemas das CIESs e da EPS especificamente, contudo são fatores a serem considerados na elaboração dos planos regionais de educação, pois o conhecimento desses 'problemas' é importante nos 'diagnósticos de necessidades educativas'. A sua resolução é uma questão de gestão, mas primordialmente também de educação no trabalho.

Por fim, destaca-se a relevância da CIES no cenário do estudo. Pois, se há intenção de mudanças nos diversos segmentos, o ponto de partida é a EPS, e as comissões de integração ensino-serviço são o espaço de discussões, de definições e, consequentemente, de geração de transformações que poderão impactar ações proativas que possam repercutir positivamente na saúde das pessoas e populações.

\section{Colaboradores}

Luiz Anildo Anacleto da Silva é o autor principal responsável pela redação completa e pelas revisões. Camila Pinno e Marinês Tambara Leite realizaram contribuições diversas e colaboraram na análise e revisão do texto. 
Resumen Las comisiones de integración enseñanza-servicio tienen un papel importante en la materialización de la Política Nacional de Educación Permanente en Salud. En este estudio cualitativo, descriptivo y exploratorio, se buscó conocer los factores que potencializan o fragilizan la construcción y el desarrollo de los planes regionales de educación permanente en la concepción de los miembros participantes de las comisiones de integración enseñanza-servicio del estado de Río Grande do Sul (Sur de Brasil). El muestreo de participantes se realizó por el método a propósito, intencional o deliberado. Los resultados muestran la importancia de estas comisiones en el desarrollo de los planes regionales de educación permanente en salud. Se consideran factores facilitadores: la participación y el compromiso de los profesionales, la estructuración de los servicios. Los factores limitantes son las dificultades de articulación, la participación y el compromiso personal e institucional, y la participación de los gestores. El compromiso de los gestores en el proceso es dual: su conocimiento y compromiso se consideran factores facilitadores, mientras que el desconocimiento y la no facilitación en la inserción en el proceso educativo se entienden como perjudiciales al desarrollo del proceso como un todo.

Palabras clave comisión de integración enseñanza-servicio; educación permanente en salud; proceso de trabajo.

\section{Notas}

1 Universidade Federal de Santa Maria, Palmeira das Missões, Rio Grande do Sul, Brasil.

Doutor em Enfermagem pela Universidade Federal de Santa Maria.

$<$ luiz.anildo@yahoo.com.br>

Correspondência: UFSM-Cesnors, Campus de Palmeira das Missões, Rua Antonio Boenig, 268, CEP 98700-000, Morada do Sol, Ijuí, Rio Grande do Sul, Brasil.

2 Universidade Federal de Santa Maria, Palmeira das Missões, Rio Grande do Sul, Brasil.

Doutora em Gerontologia pela Pontifícia Universidade Católica do Rio Grande do Sul, Porto Alegre, Rio Grande do Sul, Brasil. <tambaraleite@yahoo.com.br>

3 Universidade Federal de Santa Maria, Palmeira das Missões, Rio Grande do Sul, Brasil.

Residente do Programa de Residência Multiprofissional Integrada da Universidade Federal de Santa Maria. <camilalegal_@hotmail.com> 


\section{Referências}

ALBUQUERQUE, Verônica S. et al. A integração ensino-serviço no contexto dos processos de mudança na formação superior dos profissionais da saúde. Revista Brasileira de Educação Médica, Rio de Janeiro, v. 32, n. 3, p. 356-362, 2008.

ALMEIDA, Maria C. P.; ROCHA, Juan S. Y. O saber de enfermagem e sua dimensão prática. São Paulo: Cortez, 1986.

AZAMBUJA, Eliane P. de. O processo de trabalho e o processo educativo: construindo a prevenção da situação de risco e de acidente de trabalho. Dissertação (Mestrado em Enfermagem) - Programa de Pós-Graduação em Enfermagem, Universidade Federal de Santa Catarina, Florianópolis, 1999.

BARDIN, Laurence. Análise de conteúdo. São Paulo: Edições 70, 2011.

BARRIOS, Sueli T. G. Micropolitica e gestão regionalizada da saúde: estudo de caso no colegiado de gestão da $4^{\text {a }}$ região sanitária do estado do Rio Grande do Sul. 2009. 177 f. Dissertação (Mestrado em Enfermagem) Universidade Federal de Santa Maria, Santa Maria, 2009.

BRASIL. Ministério da Saúde. Conselho Nacional de Saúde. Resolução n. 196/96. Dispõe sobre pesquisa envolvendo seres humanos. Bioética. Brasília: Ministério da Saúde, 1996. Disponível em: <http://conselho.saude.gov. br/web_comissoes/conep/aquivos/resolucoes/ 23_out_versao_final_196_ENCEP2012.pdf>. Acesso em: 06 mar. 2012.

Ministério da Saúde. Secretaria Executiva. Núcleo Técnico da Política Nacional de Humanização. HumanizaSUS: a clínica ampliada. Brasília: Ministério da Saúde, 2004a. Disponível em: <http://bvsms.saude.gov. br/bvs/publicacoes/clinica_ampliada.pdf $>$. Acesso em: 13 mar. 2012.

Ministério da Saúde. Secretaria Executiva. Núcleo Técnico da Política Nacio- nal de Humanização. HumanizaSUS: equipe de referência e apoio matricial. Brasília: Ministério da Saúde, 2004b. Disponível em: $<$ www.redehumanizasus.net/4-a-redehumaniza-sus>. Acesso em: 2 abr. 2012.

Ministério da Saúde. Secretaria Executiva. Núcleo Técnico da Política Nacional de Humanização. HumanizaSUS: prontuário transdisciplinar e projeto terapêutico. Brasília: Ministério da Saúde, 2004c. Disponível em: <http://bvsms.saude.gov.br/ bvs/publicacoes/prontuario.pdf $>$. Acesso em: 9 abr. 2012.

Ministério da Saúde. Secretaria de Gestão do Trabalho e da Educação na Saúde. Departamento de Gestão da Educação em Saúde. A educação permanente entra na roda: polos de educação permanente em saúde conceitos e caminhos a percorrer. Brasília: Ministério da Saúde, 2005. Disponível em: $<$ http://bvsms.saude.gov.br/bvs/publicacoes/ educacao_permanente_entra_na_roda.pdf $>$. Acesso em: 6 maio 2010.

Ministério da Saúde. Portaria GM/MS n. 1.996/2007. Dispõe sobre as diretrizes para a implementação da Política Nacional de Educação Permanente em Saúde. Brasília: Ministério da Saúde, 2007. Disponível em: <www.saude.al.gov.br/ portariagmmsn 1996de20deagostode200711-03-2>. Acesso em: 9 out. 2011.

Ministério da Saúde. Secretaria de Atenção à Saúde. Política Nacional de Humanização da Atenção e Gestão do SUS: gestão participativa e cogestão. Brasília: Ministério da Saúde, 2009. Disponível em: $<$ http://bvsms.saude.gov.br/bvs/publicacoes/ gestao_participativa_co_gestao.pdf $>$. Acesso em: 10 maio 2012

FREIRE, Paulo. Pedagogia da autonomia. São Paulo: Paz e Terra, 1998.

GIL, Antonio C. Como elaborar projetos de pesquisa. São Paulo: Atlas, 1996. 
MEHRY, Emerson; FEUERWERKER, Laura C. M.; CECCIM, Ricardo. Educación permanente en salud: una estrategia para intervir en la micropolitica del trabajo em salud. Salud Coletiva, Buenos Aires, v. 2, n. 2, p. 147-160, 2006.

MINAYO, Maria C. O desafio do conhecimento. São Paulo: Hucitec, 2007.

PEREIRA, Érica G.; SOARES, Cássia B.; CAMPOS, Célia M. S. Uma proposta de construção da base operacional do processo de trabalho educativo em saúde coletiva. Revista Latino-Americana de Enfermagem, Ribeirão Preto, v. 15, n. 6, p. 1061-1071, 2007.

PIRES, Denise. Reestruturação produtiva e trabalho em saúde no Brasil. 2. ed. São Paulo: Confederação Nacional dos Trabalhadores em Seguridade Social, 2008.

RICALDONI, Carlos Alberto C.; SENA, Roseni R. de. Educação permanente: uma ferramenta para pensar e agir no trabalho em enfermagem. Revista Latino-Americana de Enfermagem, Ribeirão Preto, v. 14, n. 6, p. 837-842, 2006.

RIO GRANDE DO SUL. Secretaria Estadual de Saúde. Resolução n. 143/2007. CIB [Comissões Intergestores Bipartite] RS. Porto Alegre: Secretaria Estadual de Saúde, 2007. Disponível em: <www.saude.rs.gov.br/upload/ 1340744226_cibr143_07.pdf>. Acesso em: 11 maio 2012.

Secretaria Estadual de Saúde. Resolução n. 231/2011. CIB [Comissões Intergestores Bipartite] RS. Porto Alegre: Secretaria Estadual de Saúde, 2011. Disponível em: <www.saude.rs.gov.br/upload/1339533922_ cibr231_11.pdf>. Acesso em: 13 maio 2012.
SANTOS FILHO, Serafim B.; FIGUEIREDO, Vera O. N.. Contratos internos de gestão no contexto da Política de Humanização: experimentando uma metodologia no referencial da cogestão. Interface: Comunicação, Saúde, Educação, Botucatu, v. 13, supl. 1, p. 615626, 2009.

SILVA, Luiz A. A.; BACKES, Vânia M. S. Perspectivas de transcender na educação no trabalho: tendências da enfermagem latino-americana. Tese (Doutorado em Enfermagem) - Programa de Pós-Graduação em Enfermagem, Universidade Federal de Santa Catarina, Florianópolis, 2007.

SILVA, Luiz Anildo Anacleto da et al. Educação permanente em saúde e no trabalho de enfermagem: perspectiva de uma práxis transformadora. Revista Gaúcha de Enfermagem [on line], Porto Alegre, v. 31, n. 3, p. 557-561, 2010. Disponível em: <www. scielo.br/pdf/rgenf/v31n3/v31n3a21.pdf $>$. Acesso em: 12 jan. 2010.

TURATO, Eg berto R. Tratado da metodologia clínico-qualitativa. Petrópolis: Vozes, 2003.

VÁZQUEZ, Adolfo S. Filosofia da práxis. 2. ed. Rio de Janeiro: Paz e Terra, 1997.

Recebido em 18/07/2012

Aprovado em 07/10/2013 